\title{
Suit Yourself Customize Your Suits the Way You Want
}

\author{
Srishti Patil ${ }^{1}$, Priya Todase ${ }^{2}$, Sagar Dixit ${ }^{3}$, Ashish Chopane ${ }^{4}$, Prof. Neha Chankhore ${ }^{5}$ \\ U.G Students, Department of Information Technology, Vidyalankar Institute of Technology, Mumbai ${ }^{1,2,3,4}$ \\ Assistant Professor, Department of Information Technology, Vidyalankar Institute of Technology, Mumbai ${ }^{5}$
}

\begin{abstract}
With the growing technology, getting things do neat the tip of a finger have become very common. Everyone wants their stuff to be done quickly and easily whether it is changing television channel or ordering goods online. But when it comes to getting designed and customized suits, one does not have many options. What is observed is that user can select the parts of suit like blazer, vest, tie, bow etc. User cannot completely customize the look he wants. Suit Yourself will enable user to choose smallest of the smallest detail. In traditional user has to visit the store, get the designs from tailors, explain them what exactly he wants the suit to look like and at the same time get recommendations from the designer himself. To overcome this hectic procedure, the idea of Suit Yourself has been undertaken. Suit Yourself is a concept to customize the suit online, which will help the customer better visualize the suit in 360- degree panoramic view before its tailored and will reduce the effort of client to go to the shop and get things done.
\end{abstract}

Keywords: 360-degree panoramic, customization.

\section{INTRODUCTION}

1. Training the employees to solve any query. The traditional way of tailoring is time consuming for both Employees should know about the entire working of the tailors and clients also it requires a lot of brainstorming to company, which might become impractical sometimes. satisfy the client by just specifying the material, color etc. 2. Huge Marketing and promotional cost involved. In addition to this the end result may or may not appeal the Additionally, the user will be prompted with client. Nowadays, due to growing fashion industry recommendations, latest trends etc. This will be done by knowledge every client has his own view of his suit.

Due to expanding demands of the clients and growth of ecommerce industry CEO Rules LX has decided to go online to meet the expectations of clients. The successful launch of this project will enable client to customize his suit as per his choice. Also, going online will be of the economic benefit for company. Also, it was observed that visualizing the final look of the suit was difficult for clients therefore to aid them in visualizing the suita360degree panoramic view will be added. This will prove an additional functionality as very less e-commerce giants are getting into customization and displaying the end product. To get the user acquainted with new trends in fashion a recommending system would be implemented.

\section{LITERATURESURVEY}

The proposed prototype is intended to help the customer customize the suits. The purpose of the project is to build the bridge between designers and people. The tailoring today involves manual sketching of the outfit. This project will virtualize the suit so no manual efforts needed to sketch and visualize the look of the outfit. collaborative filtering and context aware approaches.

Collaborative Approach:

In this we will be using user based approach because our website is user driven and not content driven.

In the user-based approach, the users perform the main role. If certain majority of the customers has the same taste, then they join into one group. Recommendations are given to user based on evaluation of items by other users form the same group, with whom he/she shares common preferences. If the item was positively rated by the community, it will be recommended to the user. Thus, in the user-based approach the items that were already rated by the user before play an important role in searching a group that shares appreciations with him.

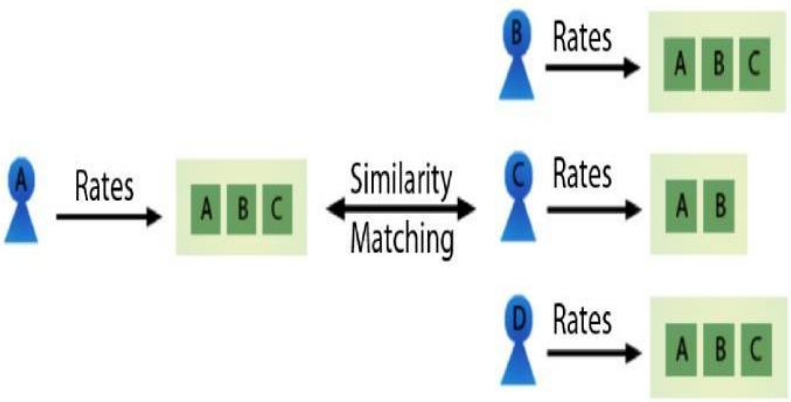

This becomes a cost for the company in two ways: 


\section{Context-aware approaches:}

Context is the information about the environment of a user and the details of situation he/she is in. Such details may play much more significant role in recommendations than ratings of items, as the ratings alone don't have detailed information about under which circumstances they were given by users. Some recommendations can be more suitable to a user in evening and doesn't match his preferences in the morning at all and he/she would like to do one thing when it's cold and completely another when its hot outside. The recommender systems that pay attention and utilize such information in giving recommendations are called context-aware recommender systems.

\section{PROBLEM}

Nowadays, people find it difficult or maybe too hectic to visit stores for shopping. And even after visiting stores, it may take a lot of time checking and trying every suit. If the person wants customized suits, then he has to manually give details and will have to imagine the view of how the final product will look.

Also from seller's end, the tailors have to be available for every customer at every time to recommend them and help them decide what will be the best choice. Also, keeping track of every customer's past purchases and visits and helping them based on their past purchases is not easy. Such manual tasks add burden to both company and customer's end.

\section{PROPOSED SYSTEM}

We propose a system where the traditional method of ordering a suit is replaced to a virtual one. Users will be able to customize their suit by their choice.

\begin{tabular}{|l|l|}
\hline Traditional Approach & Proposed System \\
\hline $\begin{array}{l}\text { The designers also } \\
\text { interfere in the } \\
\text { customization process. }\end{array}$ & $\begin{array}{l}\text { The user could customize } \\
\text { as per they want. }\end{array}$ \\
\hline $\begin{array}{l}\text { The designers have to } \\
\text { help the customer } \\
\text { visualize the outfit. }\end{array}$ & $\begin{array}{l}\text { The user could then and } \\
\text { there see the outfit. }\end{array}$ \\
\hline $\begin{array}{l}\text { Designer had to spend } \\
\text { time sketching, thus } \\
\text { slower. }\end{array}$ & $\begin{array}{l}\text { Here the frame is already } \\
\text { made, the user just tries } \\
\text { new styles thus quicker. }\end{array}$ \\
\hline $\begin{array}{l}\text { Physically visiting the } \\
\text { shop is mandatory every } \\
\text { time. }\end{array}$ & $\begin{array}{l}\text { Once the measurements } \\
\text { are done user does not } \\
\text { have to visit the shop } \\
\text { again and again to style } \\
\text { the outfit. }\end{array}$ \\
\hline
\end{tabular}

\begin{tabular}{|l|l|}
\hline Also, the latest trends & The recommendations \\
and recommendations \\
may take a backseat in \\
will always be popped up \\
since the all will be \\
the conversations \\
managed on backend. \\
designer client and
\end{tabular}

A user opens the website and selects the type of suit they want. Once the suit is selected they customize the look with fabric, buttons, cufflinks, and collar of their choice. This user selections are then processed and are combined to give a preview of the suit which is a $3600^{0}$ panoramic view. Considering what the user has selected previously the database will be fetched and recommendations will be given to them appropriately.

The major differences between the traditional system and proposed system are as follows:

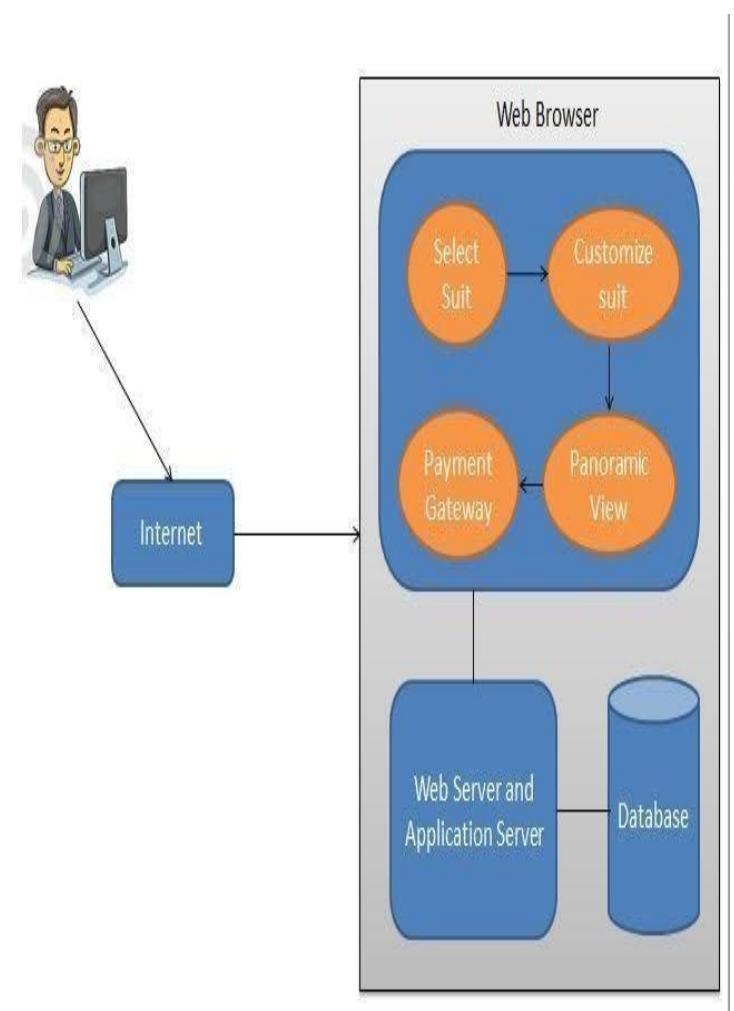

\section{CONCLUSION}

The proposed system allows users to customize suits in a hassle-free manner and have a complete look at the output product and users don't have to pay extra charges to tailors for doing that which will save time. It can be further applied to customize other clothing's as well, which will help develop the overall experience of users for online shopping. 
[1] https://www.snet.tu-berlin.de/fileadmin/fg220/courses/SS11/snetproject/recommender-systems_asanov.pdf

[2] http://www.ijcsit.com/docs/Volume\%203/Vol3Issue2/ijcsit2012030 234.pdf

[3] http://ieeexplore.iee.org/document/6330536/

[4] http://magicfabricblog.com/marvelous-design-bridges-real-patternmaking-technique-and-3d-software-together/

[5] https://www.researchgate.net/publication/271216884_Advanced_C ADCAM_systems_for_garment_design_and_simulation

[6] Bramham, J., \& MacCarthy, B. (2004). The demand driven chain [product configurator]. Manufacturing Engineer,83(3), 30-33.

[7] Colace, Francesco, Massimo De Santo, and Luca Greco."An adaptive product configurator based on slow intelligence approach." International Journal of Metadata, Semantics and Ontologies 9, no. 2 (2014):128-137.

[8] Chu, Chih-Hsing, Ching-Yi Cheng, and Che-WenWu. "Applications of the Web-based collaborative visualization in distributed product development." Computers in Industry57, no. 3 (2006):272-282.

[9] Trentin, Alessio, Elisa Perin, and Cipriano Forza. "Overcoming the customization-responsiveness squeeze by using product configurators: Beyond anecdotal evidence. "Computers in Industry 62, no. 3 (2011):260-268. 